\title{
Radiation Techniques in Neuro-Oncology
}

\author{
Deepak Khuntia,* Wolfgang A. Tomé, ${ }^{* \dagger}$ and Minesh P. Mehta* \\ Departments of *Human Oncology and ${ }^{\dagger}$ Medical Physics, University of Wisconsin-Madison, Madison, Wisconsin 53792
}

Summary: Radiation therapy plays a critical role in the management of tumors of the brain. A variety of radiotherapy techniques have been used to treat these tumors. This review describes both classic and more recent and advanced techniques available to manage these tumors. Included is a discussion of standard two- and three-dimensional radiation, as well as intensity-modulated radiotherapy, image-guided radiation therapy, stereotactic radiosurgery, and heavy particles. Key Words: Radiation, IMRT, protons, radiosurgery, gamma knife.

\section{INTRODUCTION}

The foundation of radiotherapy as a major cancer treatment modality dates back to the twin discoveries of X-rays in 1895 by Wilhelm Conrad Roentgen and of radioactivity, three years later, by the Curies. ${ }^{1}$ Roentgen noticed that passing an electrical current through a classic Crookes tube caused a line to appear on a piece of barium platinocyanide paper. When asked by a reporter of what he thought of this, he responded "I did not think; I investigated." 2 Through his investigations, X-rays were discovered and his work led to a Nobel prize in 1901. $\mathrm{X}$-rays rapidly led to the emergence of the field of teletherapy (literally, therapy at a distance), wherein cancer would be radiated "from a distance," using an X-ray tube. Shortly after the discovery of X-rays, the Curies discovered radium in 1898 , which was rapidly deployed to treat cancer, using brachytherapy (short distance) techniques. These two discoveries birthed the discipline of radiation therapy.

The field evolved throughout the 20th century, sedately at first, but then in pace with advances in physics, atomic sciences, materials sciences, engineering, and computing, until the last two decades of the century were characterized by dramatic changes (Table 1). ${ }^{3}$ Initial major developments included the discovery of X-rays, which were supplanted by cesium- 137 and cobalt- 60 teleradiation therapy devices in the 1950s and 1960s,

Address correspondence and reprint requests to: Deepak Khuntia, M.D., Department of Human Oncology, University of Wisconsin, 600 Highland Avenue, K4-B100, Madison, WI 53792. E-mail: khuntia@ humonc.wisc.edu. because of their superior beam penetration characteristics, and starting in the late 1960s, linear acceleratorbased radiation therapy became the backbone technology. This phase represented a megavoltage power race, as more and more energetic beams were sought, which would have skin-sparing properties, while delivering a high dose of radiation at depth, a trait very different from conventional kilovoltage diagnostic X-rays which deposit their maximum dose at the skin surface with rapidly diminishing dose at depth.

Linear accelerators birthed the technologies of three-dimensional (3D) conformal radiation therapy, intensitymodulated radiation therapy, and image-guided radiotherapy, such as helical tomotherapy (and other image-guided radiation modalities). The technique of radiosurgery was developed through parallel efforts on multiple fronts, but reached clinical application through shipyard engineering advances in Sweden, where multiple cobalt-60 sources were fitted into a helmet-like configuration with precision beam collimation to produce remarkably tiny and accurate beams, resulting in the concept of using very high single-fraction (i.e., single therapy session) radiation doses for the purposes of target ablation, which expanded the clinical utility beyond neoplasms into the realm of benign and functional indications.

The research focus on particle physics during the World War II and the Cold War (and more recently its offshoot, the Star Wars program) resulted in the initial development of industrial-scale charged-particle radiation therapy, and is now beginning to spur the development of compact proton devices, which could revolutionize the field in the next decade. It is hoped that advances in these technologies will enhance the therapeutic ration of 
Table 1. Radiation Oncology Timeline

\begin{tabular}{ll}
\hline 1895 & Roentgen discovers X-rays \\
1896 & Emil Grubbe treats advanced breast cancer with X-rays \\
1898 & Curies discover radium \\
1900 & First fractionated external beam radiation course used \\
1902 & First brachytherapy procedure performed in Saint Petersburg, Russia \\
1913 & W.D. Coolidge's discovery of "hot cathode tube" allows radiation quality and dose to be controlled \\
$1920 \mathrm{~s}$ & Isodose lines become available \\
$1940 \mathrm{~s}$ & Betatron invented \\
1948 & First linear electron accelerator developed by D.W. Fry et al. \\
$1950 \mathrm{~s}$ & Cobalt-60 treatment machines developed \\
1956 & Installation of the first 6-MV accelerator, Stanford University \\
1956 & Cell survival assay developed by Puck and Marcus \\
1968 & Stereotactic radiosurgery developed \\
$1970 \mathrm{~s}$ & CT developed: early 1970s \\
& MRI developed: late 1970s \\
$1980 \mathrm{~s}$ & First practical PET developed: late 1970s \\
& Intensity-modulated radiotherapy (IMRT) developed in concept, although not in common application until \\
& the 1990s
\end{tabular}

Adapted from: Bernier J, Hall EJ, Giaccia A. Radiation oncology: a century of achievements. Nat Rev Cancer 2004;4:737-747.

radiation in brain tumors; that is, higher local control with escalating doses of radiation to tumors, but reduced toxicity with more conformal radiation delivery. Here, we describe these modalities as related to neuro-oncology.

\section{D AND 3D TECHNIQUES}

Two- and three-dimensional radiation techniques have been and continue to be the mainstay of external beam radiation treatments. Prior to the advent of CT simulation and modern treatment planning software, radiation was delivered using conventional, or 2D techniques. This typically involved a clinical anatomical decision-making process, factoring in tumor location as well as the proximity of critical normal tissues and setting up, two to four orthogonal radiation beam fields on an X-ray simulator with bony anatomy providing the bulk of the guidance (FIG. 1). The target was identified on planar X-ray, and areas not to be treated were blocked, originally with lead or cerrobend (a much lighter and more pliant alloy) and more recently with multileaf collimators, converting a square or rectangular beam into an irregularly shaped beam, at least in two directions. Bony anatomy visualized on plain radiographs was the primary method of determining field placement, and generally this meant using orthogonal, and occasionally oblique or vertex fields.

The uncertainty in target determination with this rudimentary method mandated the incorporation of error as a significant element in the radiation field design, generally resulting in large volumes being irradiated. As CT technology emerged, it became possible to incorporate 3D cross-sectional data into treatment planning systems, not only to delineate targets accurately (both normal structures and tumor) but also to calculate radiation doses efficiently (FIG. 2) from multiple beams from multiple directions, and to block out normal tissue more effectively, thus yielding a more conformal 3D radiation plan (FIG. 3). Computed tomography reconstruction allows one to display beam's-eye-views (BEV), which allows visualization from the perspective of the axis of the radiation source, regardless of the direction of beam entry.

With the advent of 3D conformal radiation, radiation oncologists can accurately quantify radiation doses to the normal structures and can modify characteristics of the beam to maximize dose to the target while limiting dose to the normal structures. Consequently, the error margins

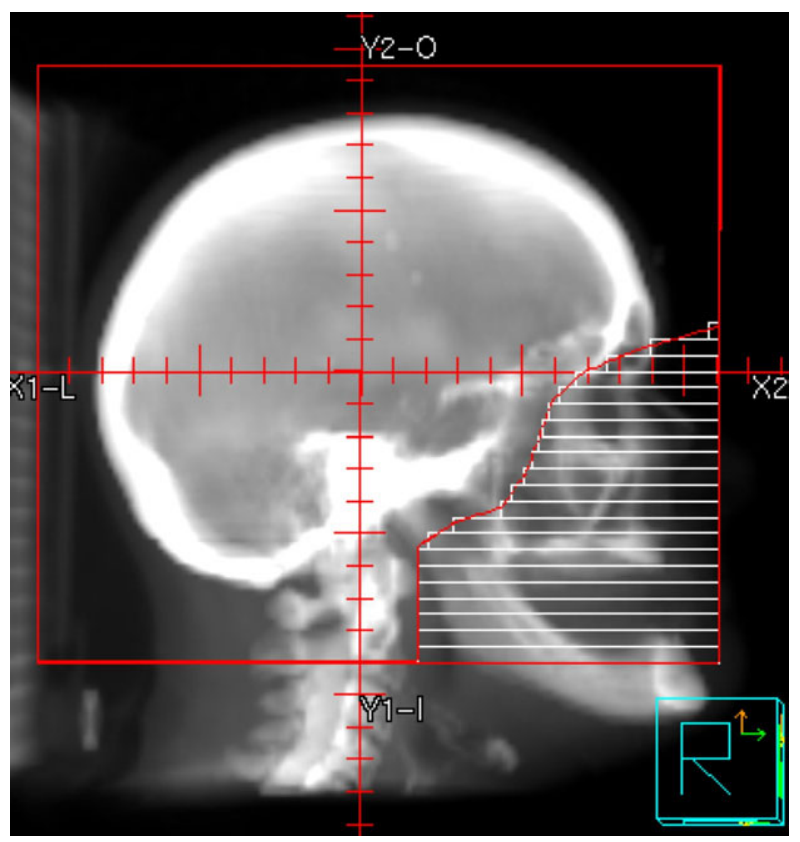

FIG. 1. Two-dimensional (2D) set-up of a whole-brain radiation field. Structures of the head and neck are blocked out by either multileaf collimators or cerrobend blocks. Measurements of the patient's width as well as field size are manually measured, to assist in calculating how to deliver the appropriate dose. 


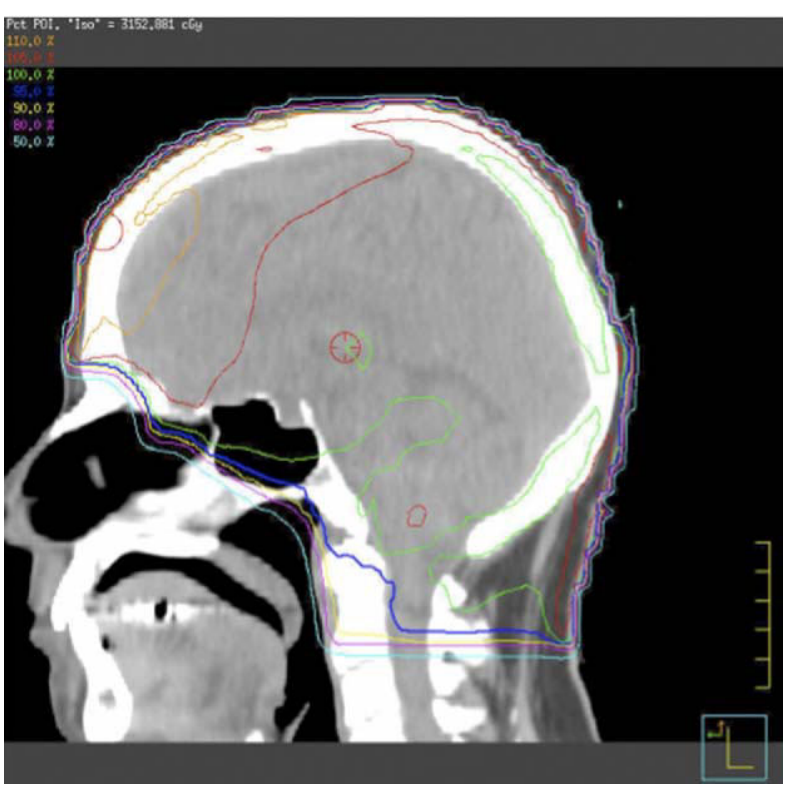

FIG. 2. Computed tomography (CT) planning allows efficient measurement of isodose lines, for more accurately determining cold and hot radiation regions within a radiation treatment field.

could be reduced, and more accurate shielding of normal structures was presumed to produce a better therapeutic ratio. Graphically, these data are represented on a dosevolume histogram (FIG. 4), an analysis that yields information pertinent to the adequacy of tumor dose and contributes to maintaining normal tissue doses below known and safe thresholds (Table 2). ${ }^{4}$ This type of radiation delivery is the most common treatment used for primary brain tumors, although use of intensity-modulated radiation therapy (IMRT) is increasing. Both 3D and IMRT involve considerably more effort and resources to delineate target and normal structures, as well as requiring precision during delivery (which in turn requires excellent immobilization, as well as the recent incorporation of image-guidance to confirm accuracy on a daily basis). The major hypothesized benefits are a reduction in the dose to normal structures, as well as the potential for dose escalation.

\section{INTENSITY-MODULATED RADIATION THERAPY}

Intensity-modulated radiation therapy was developed in the late 1980s and became widely available in the mid-1990s. This technology allows the radiation beam to be subdivided into a very large number of optimized beamlets from multiple different directions, each with a unique intensity of radiation, mimicking the patient's anatomy in the path of the beamlet and so allowing significantly improved radiation dose distributions, both to tumor and to normal tissues. With IMRT, dose distributions can be shaped three-dimensionally in concave or convex configurations, resulting in a dramatic reduction of high doses of radiation to normal structures near the target. Further, IMRT allows for differential doses to be deposited within a target, such that a component at higher risk of recurrence can be irradiated to a higher dose while the rest of the target is being treated to a conventional dose. One possible drawback, in some instances, is the increase in low doses to normal tissues. Sometimes, however, this characteristic can be exploited usefully; for example, if one were to treat residual tumor after resection, IMRT could be configured so that most of the beam entry occurs through, say, the surgical cavity, where little normal tissue is expected to be present (FIG. 5).

Other challenges exist with the use of IMRT. Because of the rapid fall-off of dose, patient immobilization and daily set-up verification become critical. Slight motion or set-up error will result in a geographic miss; in the worst case-scenario, the high dose is deposited in the critical structure designated for avoidance. Fortunately, the brain moves minimally, and standard craniofacial immobilization devices yield relatively high daily set-up accuracy (FIG. 6). Nonetheless, if proximity of a nearby critical

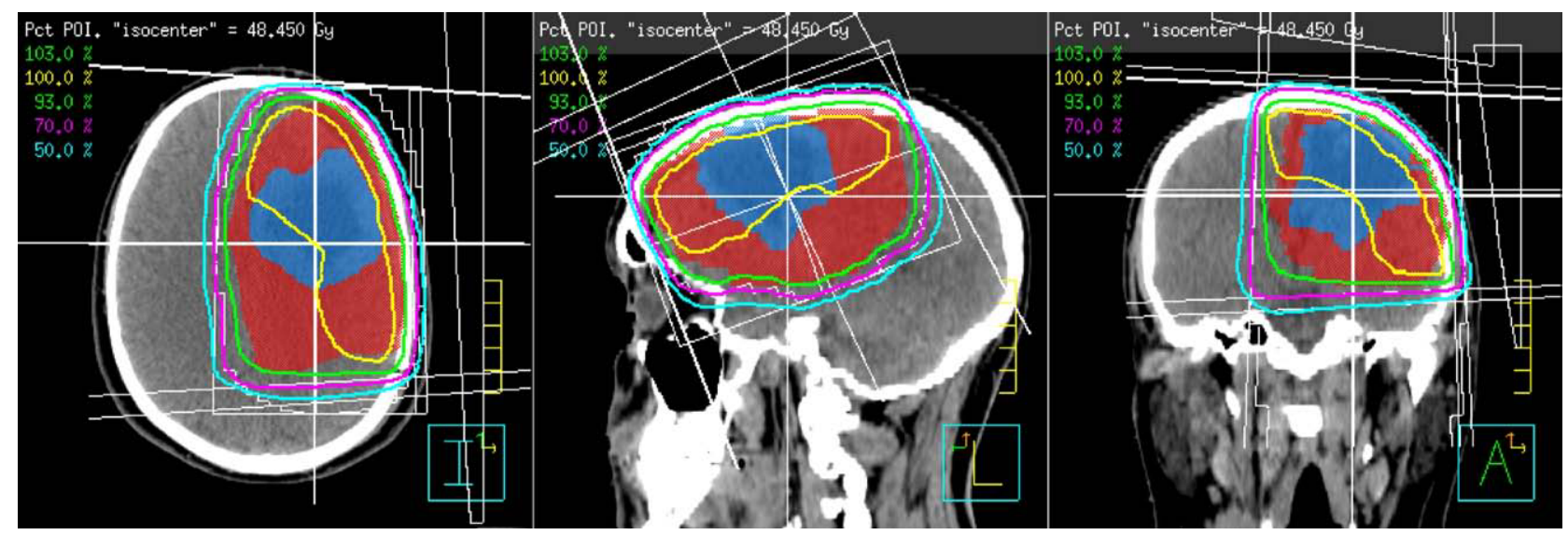

FIG. 3. Typical 3D conformal radiation plan. Wedges are used to modify the dose. The $93 \%$ isodose line is prescribed in order to cover the at risk area, delineated in red. 


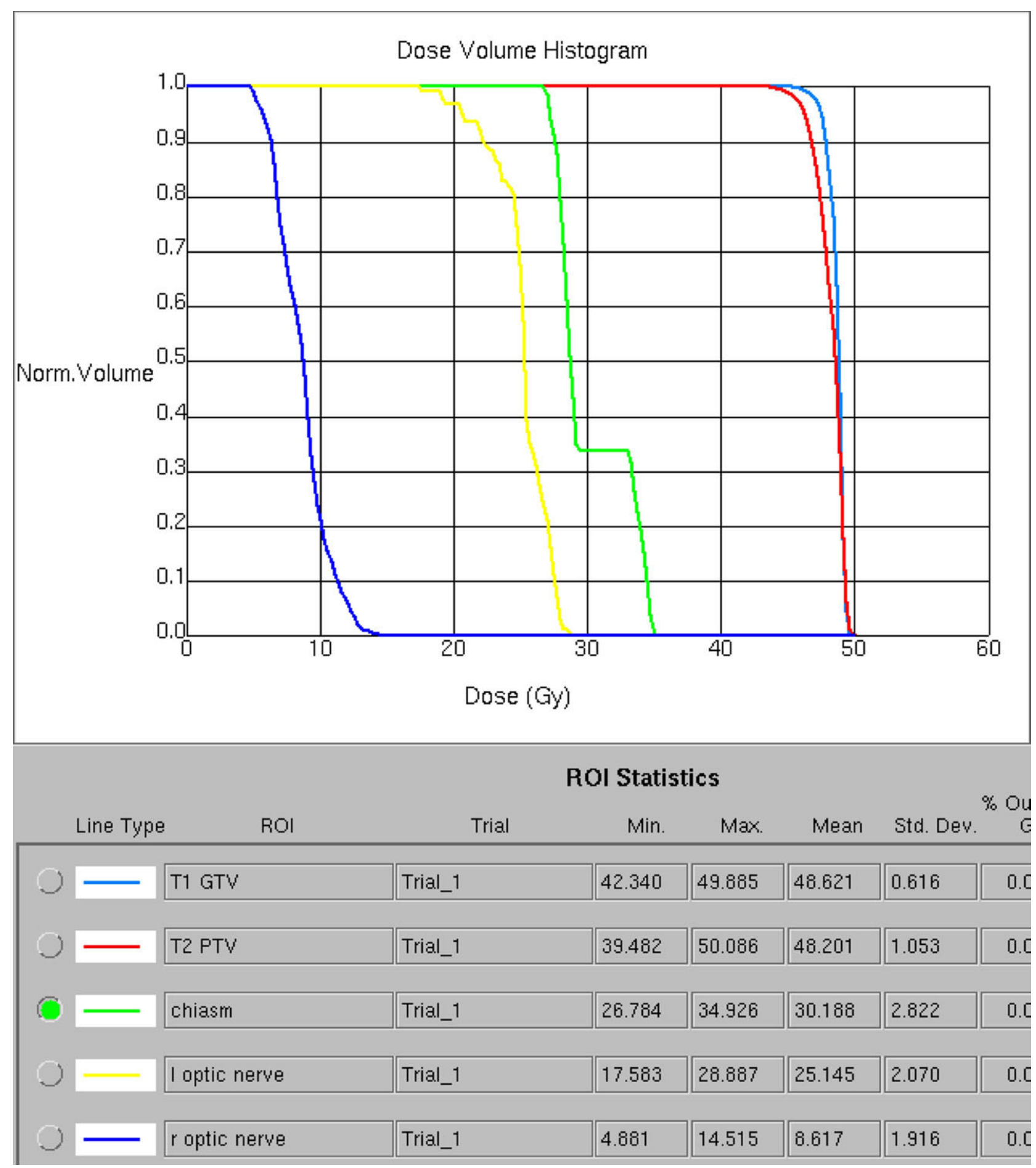

FIG. 4. Dose-volume histogram for a patient receiving 3D conformal radiation for a malignant glioma. ROI, region of interest.

structure is a concern, daily image guidance prior to therapy becomes a necessity.

Another possible feature of IMRT is dose escalating within a target, also known as a simultaneous integrated boost (SIB). This is attractive in certain situations, in that it allows a higher dose per fraction to the target, while giving a lower dose per fraction to normal structures.
Nonetheless, the potential for late injury with high dose per fraction to normal tissue does exist, which further emphasizes the need for treatment delivery accuracy. ${ }^{5}$ Because IMRT dose distributions are highly complex, it is not unusual to see unanticipated toxicities in low-dose areas, such as alopecia or mucositis, in the exit-beam regions. Finally, because of the potentially larger volume 
Table 2. Traditional Radiation Tolerances for Normal Tissue Within the Central Nervous System

\begin{tabular}{lcccccc}
\hline & \multicolumn{3}{c}{ TD5/5, cGy } & & \multicolumn{2}{c}{ TD50/5, cGy } \\
\cline { 2 - 5 } Organ & Whole & $2 / 3$ & $1 / 2$ & & Whole & $2 / 3$ \\
\hline Brain & 4500 & 5000 & 6000 & 6000 & 6500 \\
Brain stem & 5000 & 5300 & 6000 & 6000 & - \\
Ear (acute serous otitis) & 3000 & 3000 & 3000 & 4000 & 4000 \\
Ear (chronic otitis) & 5500 & 5500 & 5500 & 6500 & 6500 \\
Lens & 1000 & - & - & 1800 & - \\
Optic chiasm & 5000 & - & - & 6500 & - \\
Retina & 4500 & - & - & 6500 & - \\
Spinal cord & $4700^{*}$ & $5000^{\dagger}$ & $5000^{\dagger}$ & - & 7000 \\
\hline
\end{tabular}

Note that, as we improve our understanding of normal tissue repair, certain structures may have higher tolerances than indicated here.

$\mathrm{TD} 5 / 5=$ toxicity risk of 5 percent at 5 years; TD $50 / 5=$ toxicity risk of $50 \%$ at 5 years.

Adapted from: Emami B, Lyman J, Brown A, et al. Tolerance of normal tissue to therapeutic irradiation. Int J Radiat Oncol Biol Phys 1991;21:109-122.

$* 20 \mathrm{~cm}$.

$\dagger 10 \mathrm{~cm}$.

$\$ 5 \mathrm{~cm}$.

receiving low doses of radiation, it is conceivable that the long-term risk of second malignancies may be higher. Because this typically takes years or even decades to develop, and because there has not yet been sufficient time since the adoption of IMRT to evaluate these possibilities, it remains unclear whether second malignancies are a real or a hypothetical risk. ${ }^{6}$

Intensity-modulated radiotherapy has several potential benefits in specific CNS tumors. Medulloblastoma, the most common pediatric primary brain tumor, represents a good example. Patients with medulloblastoma are frequently treated with a multimodality approach including surgery, cisplatin-based chemotherapy, and radiation. Both chemotherapy and radiotherapy can significantly contribute to the occurrence of ototoxicity, however. Use of IMRT allows sparing of the auditory apparatus while still maintaining full dose to the target. Huang et al. ${ }^{7}$ reported a reduction in cochlear dose from 54.2 to 36.7 Gy and a reduction of grade 3 or 4 hearing loss from $64 \%$ to $13 \%$ with the use of IMRT, compared with conventional radiation therapy. Nonetheless, routine use of IMRT should be tempered, given that costs are substantially higher, because prospective data supporting its routine use are lacking. Furthermore, IMRT has a higher integral dose (i.e., higher total dose of a large volume), and there little data are available as to whether there is a negative consequence of this in the long term.

\section{IMAGE-GUIDED RADIATION THERAPY}

As already noted, daily set-up immobilization and verification of set-up accuracy are critical for IMRT. Imageguided radiation therapy (IGRT), the technique of using imaging technology at the time of each treatment to verify accurate positioning, has become critically important, given that IMRT is used to escalate the dose to tumor as well as to reduce the margin of error around the tumor in order to reduce toxicity. The several types of IGRT systems include cone-beam CT, megavoltage CT (helical tomotherapy, for example), ultrasound guidance for prostate cancer, CT-on-Rails, Calypso fiducial monitoring, and the use of electronic portal imaging devices (EPIDs). Advances in IGRT have allowed selective boost of dose to some targets while at the same time selectively sparing normal structures more aggressively. An example of this approach has been presented by Gutierrez et al. ${ }^{8}$ for the case of selective boosting of brain metastases to twice the whole-brain dose while reducing the dose to the hippocampi to $20 \%$ of the whole-brain dose, leading to a dose differential between target structures and normal tissue structures of 10 . This is achieved using helical tomotherapy, a prototypical IMRT-IGRT system with the expectation that reduction of hippocampal dose will prevent neurocognitive decline in patients receiving whole-brain radiation therapy (WBRT) (FIG. 7) ${ }^{9}{ }^{910}$ Prospective studies evaluating this approach are currently underway.

\section{STEREOTACTIC RADIOSURGERY AND FRACTIONATED STEREOTACTIC RADIOTHERAPY}

Radiosurgery was first described in 1951 by Lars Leksell, a neurosurgeon at the Karolinska Institute in Stockholm. ${ }^{11}$ The term radiosurgery was selected because of its similarity to stereotactic neurosurgery. Leksell's original work included the treatment of patients with functional disorders and benign conditions such as chronic pain and arteriovenous malformations, but later included benign and malignant tumors. The first gamma knife treatment was conducted in 1968. ${ }^{12}$ Because of its prohibitive cost and limited availability, the spread of this technology was rather 


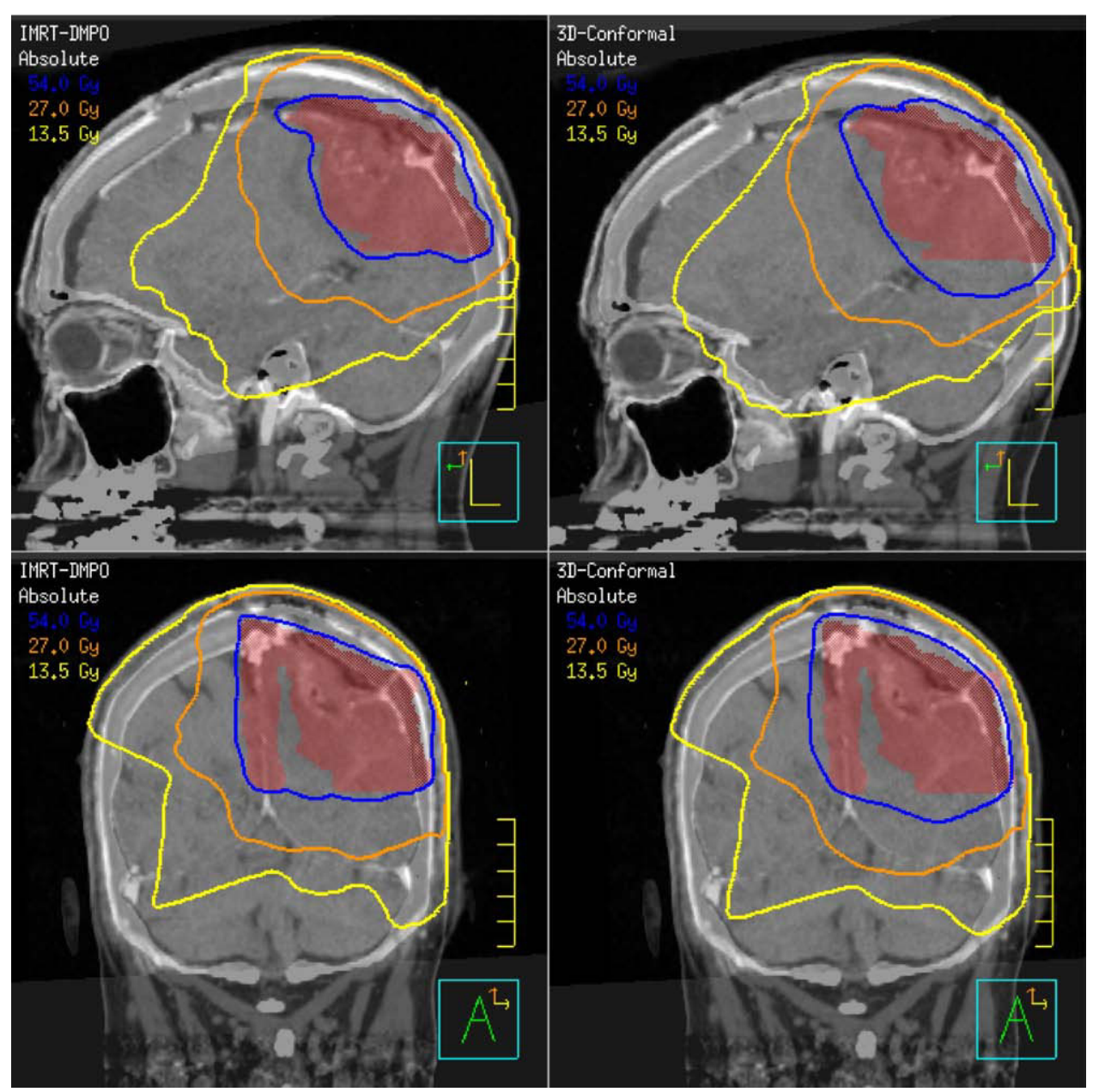

FIG. 5. Comparison of 3D plan vs intensity-modulated radiotherapy (IMRT) plan indicates more conformal radiation delivery with IMRT to the target, with additional sparing of the base of skull, especially the pituitary.

slow at first. As linear particle accelerator-based radiosurgery systems and improved imaging technology developed, however, interest in stereotactic radiosurgery (SRS) dramatically increased. Most major cancer centers in the United States now have the capability of delivering SRS.

Radiosurgery differs from conventional fractionated radiotherapy in several ways. By definition, radiosurgery implies a single treatment, whereas conventional radiation therapy involves multiple treatments. Further, in conventional fractionation regimens, normal brain tissue adjacent to the target receives nearly the full dose of radiation. Because normal brain parenchyma is relatively unforgiving in terms of late toxicity, the ability of radiosurgery to treat with high-dose gradients adjacent to a nonmobile target makes its use in the brain ideal. The use of a very large number of beams (or significantly modulated beams) ensures that no single beam on its own contributes a significant portion of the dose, and this minimizes dose to normal tissues in its path. This geometry provides physical dose distribution that is ideal for targets less than $4 \mathrm{~cm}$ in greatest dimension. Beyond $4 \mathrm{~cm}$, it is difficult to achieve a rapid fall-off in surrounding normal tissues.
A variety of commercial hardware systems are available for SRS. Radiosurgery can be performed using various devices, including the gamma knife, particle beam devices, or modified linear accelerators (e.g., Cyberknife, TomoTherapy, and Novalis) (Table $3)$. With technologic advances in software and hardware, there is no clear advantage of one technology over the other. ${ }^{13}$ Because the linear accelerator-based units can serve to treat nonradiosurgery patients during its downtime, these units have become more popular, especially where limited numbers of patients would be treated with SRS. ${ }^{13}$

Radiosurgery and neurosurgical approaches are often complimentary, but there are key differences. Radiosurgery does not require a craniotomy, and hence general anesthesia is not required and patients are usually discharged the same day. In a cost-effectiveness and cost-utility analysis by Mehta et al. ${ }^{14}$ in the 1990s, the authors showed that the average cost per week of survival for single brain metastasis was $\$ 310$ for radiotherapy, $\$ 524$ for resection plus radiation, and only $\$ 270$ for radiosurgery plus WBRT. (With the 


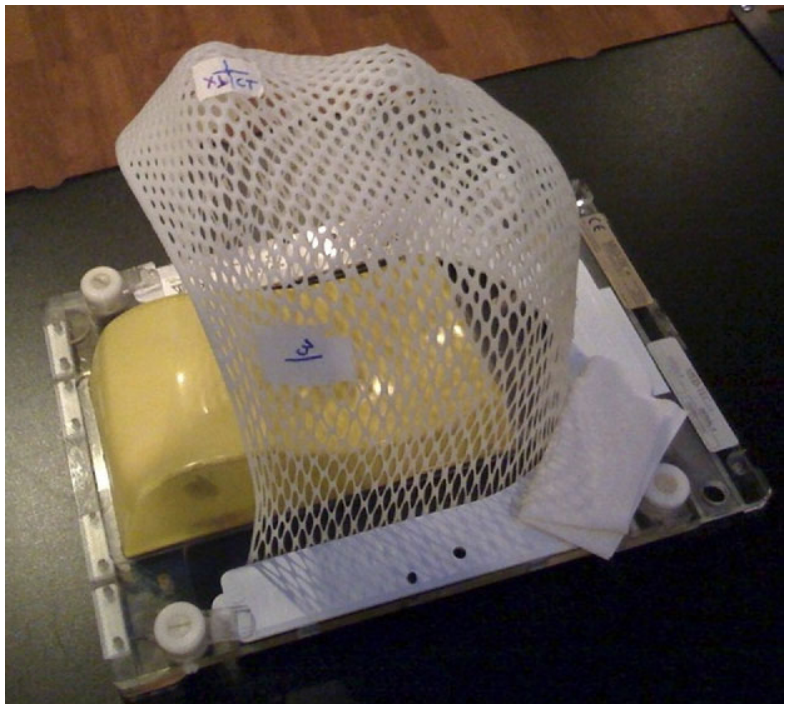

FIG. 6. Standard Aquaplast mask used for external beam treatments. Further immobilization is achievable with reinforced masks (not shown).

advent of shorter hospital stays after neurosurgical procedures, these numbers have probably changed somewhat.) Other advantages include lower postoperative risks for bleeding or infection, and also rapid recovery times. Patients who are employed prior to treatment often can return to work within a few days of the procedure. More importantly, neurosurgically inaccessible lesions and patients who are deemed unfit for surgery or anesthesia can often be treated with radiosurgery.

As radiosurgery technology has become increasingly more available, its application has widened. Current indications include arteriovenous malformations, benign brain tumors, malignant brain tumors, and functional disorders (Table 4). With the ability to localize targets outside the cranium, interest in extracranial radiosurgery is developing, with maturing reports of experience in treating pulmonary nodules (metastatic and primary), spinal and paraspinal tumors, and hepatic tumors. Typically, these treatments are fractionated ( 2 to 5 fractions), to reduce some of the potential toxicity of the high dose in single-fraction treatments.

Delivery of radiosurgery is complex and coordination of care by the neurosurgeon, radiation oncologist, and medical physicist is paramount. Appropriate coordination of care leads to improved quality of care, reduction in practice variation, and improved patient satisfaction. Each specialty brings unique skills necessary for a successful radiosurgery program. ${ }^{15}$

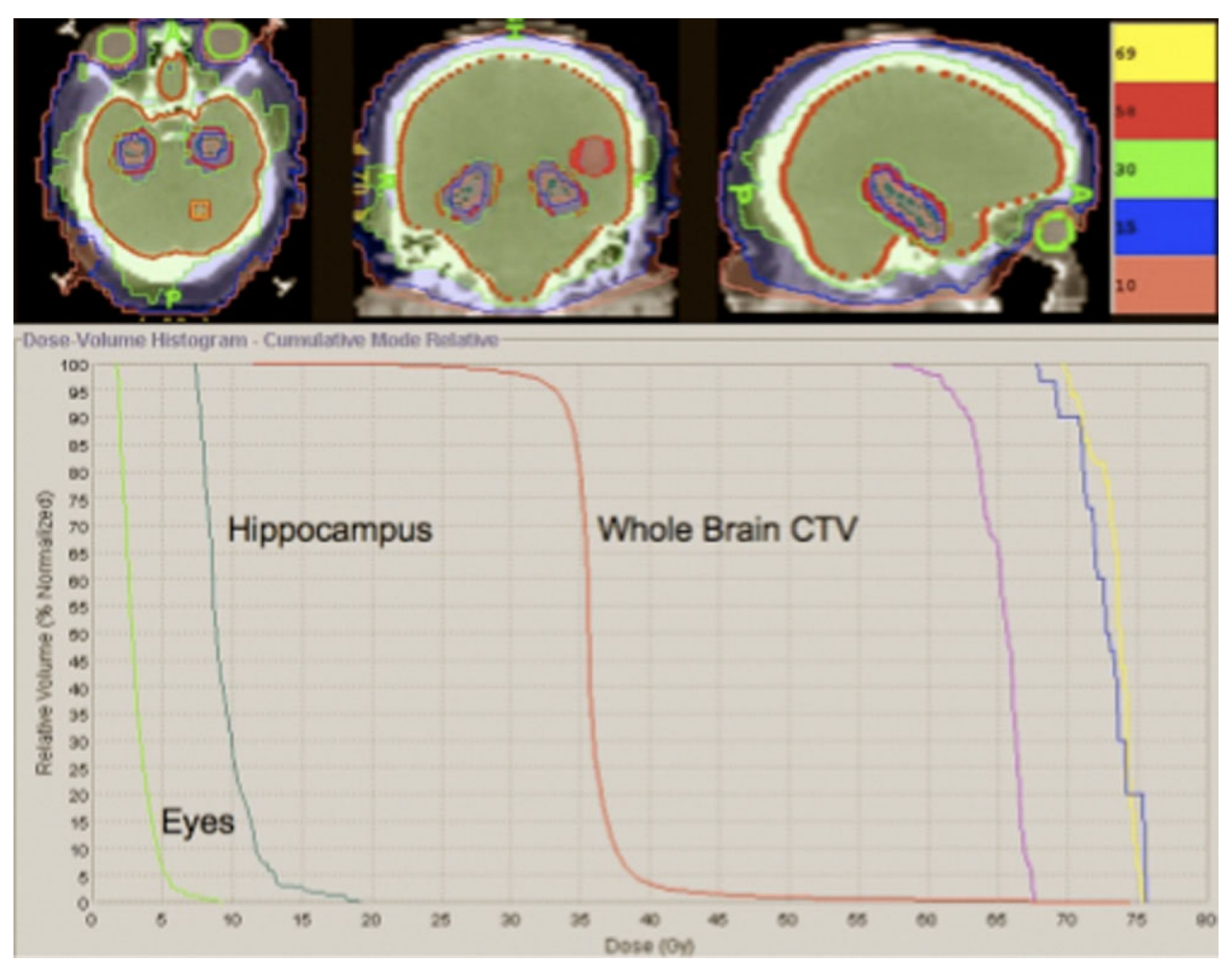

FIG. 7. Conformal hippocampal avoidance during whole-brain radiotherapy treatment plan and corresponding dose-volume histogram in which the hippocampal region is conformally avoided. One of the visible metastases received a boost of 3.86 Gy per fraction for 15 fractions, yielding a total dose of $57.9 \mathrm{~Gy}$, and two others received a boost of 4.58 Gy per fraction for 15 fractions, yielding a total dose of 68.7 Gy. The 69 Gy (yellow), 58 Gy (red), 30 Gy (green), 15 Gy (blue), and 10 Gy (rose) isodose lines are shown. The structures shown in the dose-volume histogram are, from left to right: eyes (green), hippocampus (green-blue), whole brain (red), left temporal metastasis (magenta), left parasagittal metastasis (yellow), and cerebellar metastasis (blue). 
Table 3. Novel Radiation Delivery Devices

\begin{tabular}{|c|c|}
\hline Device & Description \\
\hline $\begin{array}{l}\text { CT-on-Rails (Siemens, } \\
\text { Concord, CA) }\end{array}$ & $\begin{array}{l}\text { A unit that incorporates a kilovoltage CT scanner with a linear accelerator. The patient is } \\
\text { scanned on CT for image guidance. The table is then rotated } 180^{\circ} \text { and the patient is } \\
\text { treated on the adjacent linear accelerator. This allows additional certainty in target } \\
\text { localization. }\end{array}$ \\
\hline $\begin{array}{l}\text { TomoTherapy HI-ART } \\
\text { (TomoTherapy, } \\
\text { Madison, WI) }\end{array}$ & $\begin{array}{l}\text { A unit that incorporates a megavoltage CT scanner as a delivery device. Unlike CT-on-Rails, } \\
\text { this unit not only can scan the patient prior to treatment for target delineation but can also } \\
\text { deliver radiation. There is a high degree of beam modulation (leaves adjust at } 300 \mathrm{~cm} \text { per } \\
\text { second, which is much higher than any other delivery device), allowing for highly } \\
\text { conformal radiation dose delivery. }\end{array}$ \\
\hline Volumetric arc therapy & $\begin{array}{l}\text { Volumetric modulated arc therapy is a new way of delivering IMRT that combines 3D } \\
\text { volumetric imaging with arc treatment delivery. This technique allows for IGRT with } \\
\text { significantly reduced treatment times. Currently, volumetric arc technology is available } \\
\text { through Elekta (VMAT; Stockholm, Sweden) and Varian (RapidArc; Palo Alto, CA). }\end{array}$ \\
\hline $\begin{array}{l}\text { Gamma knife (Elekta, } \\
\text { Stockholm, Sweden) }\end{array}$ & $\begin{array}{l}\text { A dedicated stereotactic radiosurgery unit used primarily to treat lesions in the brain. Cobalt- } \\
60 \text { is the radiation source. This technology has had the longest track record for } \\
\text { radiosurgery in the brain. }\end{array}$ \\
\hline $\begin{array}{l}\text { CyberKnife (Accuray, } \\
\text { Sunnyvale, CA) }\end{array}$ & $\begin{array}{l}\text { A linear particle accelerator-based radiosurgery unit that includes a 6-MV linear accelerator } \\
\text { mounted onto a robot that allows radiation to be delivered with submillimeter accuracy in } \\
\text { virtually any direction. There are on-board image detectors for target delineation. }\end{array}$ \\
\hline $\begin{array}{l}\text { Novalis (BrainLAB, } \\
\text { Feldkirchen, Germany) }\end{array}$ & $\begin{array}{l}\text { A radiosurgery system that uses a } 120 \text { mini multileaf collimator }(2.5 \mathrm{~m}) \text { to modulate the } \\
\text { beam, which is mounted on a standard Varian linear accelerator. On-board detectors are } \\
\text { used to ensure reproducible set-up. Often, a frameless radiosurgery delivery is } \\
\text { incorporated. }\end{array}$ \\
\hline MRI-guided therapy & $\begin{array}{l}\text { Multiple MRI-guided machines are under development. The Renaissance RT system } \\
\text { (ViewRay, Gainesville, FL) will have an on-board } 0.3 \text {-T open MRI system with real-time } \\
\text { image and/or dose guidance during treatment delivery. This system will be capable of } \\
\text { delivering IMRT, intensity modulated radiosurgery, 3D conformal photon beam therapy } \\
\text { using three treatment heads that are spaced apart by } 120^{\circ} \text { with cobalt- } 60 \text { sources. }\end{array}$ \\
\hline
\end{tabular}

IGRT = image-guided radiation therapy; IMRT = intensity-modulated radiation therapy; 3D $=$ three-dimensional.

\section{INDICATIONS FOR SRS}

Indications for SRS in the brain can be subdivided into four categories: benign tumors, malignant tumors, vascular tumors, and functional disorders. Detailed commentary for each indication is beyond the scope of this review, but a brief summary is provided here.

\section{Benign tumors}

Meningioma. The two largest series investigating the role of SRS for meningiomas are from the Mayo Clinic and the University of Pittsburgh, with more than 350 patients in the two series combined; local control in excess of $90 \%$ for benign meningiomas was reported. ${ }^{16-18}$ Typical median marginal doses are between 12 Gy and 18 Gy in a single fraction. ${ }^{19-21}$ Because these data are for the most part retrospective, they need to be approached with circumspection. In a recent summary of the literature, Rogers and Mehta $^{22}$ reported local control rates in excess of $90 \%$ in more than 1000 patients treated with SRS. Further prospective evaluation of the management of meningiomas is expected in the near future through cooperative groups, such as the Radiation Therapy Oncology Group (RTOG).

Vestibular schwannoma. Traditionally, microsurgery is the treatment of choice, but SRS is an increas- ingly used option. The typical radiation dose is $12 \mathrm{~Gy}$ to 14 Gy in a single fraction. ${ }^{23}$ Pollock et al. ${ }^{24}$ reviewed 87 patients with unilateral vestibular schwannomas less than $3 \mathrm{~cm}$. In this matched-pair analysis, comparing microsurgery and radiosurgery, patients undergoing SRS were found to have improved facial nerve and hearing preservation, with decreased morbidity. Tumor control was $98 \%$ for surgery, compared with $94 \%$ for radiosurgery; hearing was preserved in $14 \%$ of the surgery patients and $75 \%$ of the radiosurgery patients. Facial nerve preservation was observed in $83 \%$ of the radiosurgery group, compared with $63 \%$ in the surgery group. There also was a trend favoring radiosurgery in terms of patient satisfaction and functional outcomes. Similar results have been found by others, and SRS has become a popular treatment in a properly selected group of patients. ${ }^{25}$

To reduce complications, especially neuropathies, fractionated SRS has been investigated. Williams ${ }^{26}$ reported on 80 consecutive patients treated with fractionated radiosurgery. Patients with tumors less than $3 \mathrm{~cm}$ received $25 \mathrm{~Gy}$ in 5 fractions and patients with tumors greater than $3 \mathrm{~cm}$ received $30 \mathrm{~Gy}$ in 10 fractions. There was no facial weakness or hearing loss in the 80 patients studied. Others have found similar hearing rates, in the range of $80 \%$ to $85 \%$ using more conventional fraction- 
Table 4. Indications for Radiosurgery

\begin{tabular}{|c|c|c|c|}
\hline Vascular $(\sim 15 \%)$ & Benign Tumors $(\sim 30 \%)$ & Malignant Tumors $(\sim 45 \%)$ & Functional Disorders $(\sim 10 \%)$ \\
\hline $\begin{array}{l}\text { Arteriovenous } \\
\text { malformations }(95 \%)\end{array}$ & Meningiomas (45\%) & Metastasis $(65 \%)$ & Trigeminal neuralgia $(90 \%)$ \\
\hline \multirow[t]{3}{*}{$\begin{array}{l}\text { Cavernous angiomas } \\
\text { and other vascular } \\
\text { lesions }(5 \%)\end{array}$} & $\begin{array}{l}\text { Vestibular schwannomas } \\
\quad(30 \%)\end{array}$ & $\begin{array}{l}\text { Glioblastoma multiforme, } \\
\text { low-grade astrocytomas, } \\
\text { and recurrent gliomas } \\
(30 \%)\end{array}$ & \multirow[t]{3}{*}{$\begin{array}{l}\text { Cluster headaches, obsessive } \\
\text { compulsive disorder, } \\
\text { Parkinson's disease, and } \\
\text { epilepsy }(10 \%)\end{array}$} \\
\hline & Pituitary adenomas (15\%) & $\begin{array}{l}\text { Choroidal melanomas and } \\
\text { other malignant tumors } \\
(5 \%)\end{array}$ & \\
\hline & $\begin{array}{l}\text { Craniopharyngiomas, } \\
\text { chemodectomas }(10 \%)\end{array}$ & & \\
\hline
\end{tabular}

Adapted from: Khuntia D, Tomé WA, Suh JH, Mehta MP. Stereotactic radiosurgery. In: Gunderson LL, Tepper JE (eds). Clinical radiation oncology. 2nd ed. New York: Elsevier; 2007.

ation regimens $(50$ Gy in 25 fractions to 57 Gy in 23 fractions). ${ }^{27,28}$ Meijer et al. ${ }^{29}$ in the Netherlands prospectively evaluated 129 patients with vestibular schwannomas who received either 20 to 25 Gy in 4 to 5 fractions if they were dentate (80 patients) versus 10 to $12.5 \mathrm{~Gy}$ in a single fraction if they were edentate (49 patients). This study revealed a four-fold increase in cranial nerve $\mathrm{V}$ complications with single fraction radiosurgery compared with fractionated radiation $(8 \%$ vs $2 \%)$. Based on such data, most investigators regard radiosurgery and fractionated radiotherapy as having comparable efficacy.

Pituitary adenoma. Ten percent of intracranial neoplasms arise in the pituitary region, and radiation is generally reserved for patients who have incompletely resected, medically inoperable, or recurrent tumors. Based on the size and location, either stereotactic radiosurgery or conformal external beam radiation may be considered. Typical radiosurgery doses are in the range of $13 \mathrm{~Gy}$ to $14 \mathrm{~Gy}$ for nonsecreting tumors, although higher doses are used for Cushing's syndrome and acromegaly. ${ }^{30}$ Local control using radiosurgery is generally in excess of $90 \%$ for nonsecretory tumors. For patients who are on hormone-suppressing therapies, markedly inferior control rates have been seen in several series, which could be explained by possible underestimation of tumor size. ${ }^{31,32}$ In growth-hormone secreting adenomas, SRS is potentially curative, and clinical trials exploring this are in development.

\section{Vascular tumors}

Arteriovenous malformations (AVMs) are aberrant clusters of arteries and veins that shunt blood from the arterial system to the venous system without an intervening capillary network. If left untreated, there is a risk of hemorrhage of approximately $1 \%$ to $4 \%$ per year, and this is associated with approximately $10 \%$ mortality and $40 \%$ morbidity over a patient's lifetime. Treatment is often considered even in an asymptomatic patient, to avoid this risk. Surgery is the treatment of choice, whenever feasible, because it immediately removes the risk of hemorrhage. If the volume of the nidus is small, however, and if the location renders it inoperable, then radiosurgery is a safe and effective alternative. The high dose of radiation presumably unleashes a cytokine cascade that induces endothelial proliferation and eventual obliteration of the AVM nidus, over 1 to 3 years. Typical doses used are in the range of $15 \mathrm{~Gy}$ to $30 \mathrm{~Gy}$, and complete obliteration of the nidus leading to control of the AVM has been reported in more than $80 \%$ of patients. ${ }^{33}$

Other vascular lesions treated with SRS with some success include cavernous hemangiomas, occult AVMs, and carotid-cavernous fistulae, among others.

\section{Malignant tumors}

Brain metastasis. Brain metastasis continues to be the most common intracranial neoplasm, with more than 100,000 cases reported annually. Stereotactic radiosurgery has been used more for brain metastasis than any other malignant tumor. Here, we will briefly describe the rationale for radiosurgery for brain metastasis.

Dose selection parameters for treating brain metastases were defined in part by a phase I RTOG trial. ${ }^{34}$ As a result of this trial, typical recommended doses for brain metastasis are based on maximal diameter: $21 \mathrm{~Gy}$ to 24 Gy for lesions $\leq 2 \mathrm{~cm}, 18$ Gy for lesions $2 \mathrm{~cm}$ to $\leq 3 \mathrm{~cm}$, and $15 \mathrm{~Gy}$ for lesions $3 \mathrm{~cm}$ to $4 \mathrm{~cm}$. Recently, the RTOG reported results from a randomized trial of WBRT (37.5 Gy/15 fractions) with or without radiosurgery. The results suggest a survival benefit for patients with single brain metastases. Additionally, post hoc subgroup analysis suggests the potential for benefiting some patients with up to three brain metastases. ${ }^{35,36}$

Glioma. Stereotactic radiosurgery for gliomas has been reserved largely for focally recurrent disease. Many patients with malignant gliomas have large tumors, often with significant edema that harbors microscopic disease, reducing the likelihood of success with radiosurgery. In 
an effort to delineate the role of SRS, the RTOG conducted a randomized trial of 203 patients with newly diagnosed glioblastoma who received either 60 Gy external beam radiation at $2 \mathrm{~Gy} /$ fraction with carmustine (also known as BCNU) versus SRS prior to external beam radiation with carmustine. ${ }^{37}$ Radiosurgery as performed on this trial did not add to overall survival, quality of life, or neurologic function.

Stereotactic radiosurgery for recurrent malignant gliomas has been reported from small institutional series. ${ }^{38}$ Currently, no prospective studies have defined its role adequately, although data suggest that some subsets of patients may benefit from the treatment. Thus, the role of radiosurgery for malignant gliomas is limited. Patients with small-volume recurrent disease may be candidates for this modality.

\section{Functional disorders}

Trigeminal neuralgia. Trigeminal neuralgia is characterized by intractable, episodic, paroxysmal facial pain; it affects approximately 150,000 people worldwide each year. What causes trigeminal neuralgia remains unknown, although the prevailing idea is that pressure against the trigeminal nerve near the pons by adjacent vessels is the culprit. Typically, medications such as carbamazepine are the treatment of choice. For patients who are refractory to medications, microvascular decompression, balloon compression, glycerol rhizotomy, and radiofrequency rhizotomy have been used, all with some success.

For patients refractory to medication, radiosurgery is the next least invasive procedure. Typical doses are 70 Gy to 90 Gy in a single fraction directed at the root entry zone of cranial nerve $\mathrm{V}$ into the pons. It is thought that delivering high doses of radiation to this region will induce a block of the sympathetic transmission through the pain fibers only. Sensorimotor function, however, is spared. After SRS, approximately $70 \%$ of patients experience some pain relief, with approximately $40 \%$ experiencing complete pain relief and coming off all medications. ${ }^{39}$ Patients with typical symptoms (i.e., sharp, electric shock-like pains, as opposed dull aching or burning pain) have superior results, compared with those who have atypical symptoms. Also, patients with no previous surgical manipulations have a higher likelihood of complete pain relief.

Other functional disorders. Other functional disorders treated with radiosurgery include cluster headaches, obsessive compulsive disorder (OCD), Parkinson's disease, intractable pain syndromes, and epilepsy. Standard SRS recommendations for these disorders have not yet been developed, and conclusive evidence of efficacy has not been established.

\section{PROTONS AND HEAVY PARTICLES}

Currently, photons and electrons are the primary therapeutic radiation modalities. Photons are massless, and electrons have a mass of a mere $9.1 \times 10^{-31} \mathrm{~kg}$. This is in sharp contrast to protons, neutrons, and other heavy particles, whose mass is in excess of $1.6 \times 10^{-27} \mathrm{~kg}$. Particle-beam radiotherapy is often used to describe therapy using protons, neutrons, alpha particles, or heavier particles, such as carbon ions. The therapy is further characterized as either high or low linear energy transfer (LET), depending on the amount of energy deposited over a given distance. Standard photon and electron radiation techniques are considered low LET in the range of 0.2 to $2 \mathrm{keV} / \mu \mathrm{m}$, as opposed to fast neutrons, which have a 10 -fold to 100 -fold higher LET. Protons and alpha particles have low LET, like photons and electrons, whereas carbon ions have high LET. The relative biologic effectiveness (RBE) is defined as the ratio of the dose of cobalt- 60 radiation to the dose of any other type of radiation that produces the same biologic endpoint and is related to the LET. For photons and electrons, the RBE is 1 . For protons and alpha particles it is slightly higher, at 1.1 to 1.2. For fast neutrons and other high-LET particles, the RBE can be between 3 to 8 .

\section{Fast neutron therapy}

Fast neutron therapy has been used since the 1930s to treat cancers. ${ }^{40}$ Initial experience showed major late sequelae, leading to a better understanding of the RBE and a lowering of doses used. Approximately 30,000 patients have been treated with this technology. However, because of the associated late adverse effects, the expense associated with creating neutron delivery systems, and advances in other radiation technology, interest in and access to neutron centers is limited. Currently, there are only five operating centers worldwide, three of them in the United States. Areas where neutrons have shown potential benefits include salivary gland tumors (specifically, adenoid cystic carcinoma), ${ }^{41-43}$ squamous cell carcinomas of the head and neck, ${ }^{44,45}$ non-small cell lung cancer, ${ }^{46}$ prostate cancer, ${ }^{47-49}$ and sarcomas. ${ }^{50}$

\section{Charged particles}

Recently, charged particle therapy, especially proton beam therapy, has been gaining interest in the radiation oncology community. This is related primarily to some of the dosimetric advantages of protons. With protons, and other charged particles, energy tends to deposit rapidly in a narrow range, at the end of its path length as the particle slows. This phenomenon, known as the Bragg peak, has the advantage of delivering radiation with a rapid fall-off, which confines the radiation to a smaller area and reduces the exit dose. The possibility of spraying low doses of radiation to normal tissues, as seen with IMRT, is less of a concern with protons, because they 
stop at a given depth that depends on their initial energy. This concept is illustrated in FIG. 8: a fractional depth dose in water of a $170 \mathrm{MeV}$ pencil proton beam has a full-width half-maximum of $8 \mathrm{~mm}$. Looking at the associated proton pencil beam, one can clearly appreciate that most of the energy is deposited at the end of the range, at the Bragg peak. The dose fall-off beyond the Bragg peak is very rapid, and the dose falls to zero within a few millimeters beyond the maximum. Proton fractional depth doses have also been referred to as inverted photon depth doses, because they deposit the maximum dose at depth, whereas photon beams deposit the maximum dose at a shallow depth.

Currently, there are 6 centers in the United States and 26 installations worldwide. The earliest centers began treating patients in 1969 , and more than 60,000 patients have been treated worldwide.

Current proton treatment centers use either a largescale cyclotron or a synchrotron to produce proton beams with peak energies ranging from $230 \mathrm{MeV}$ to $240 \mathrm{MeV}$. The beam can be fed sequentially to a number of treatment rooms. These machines are often limited by being unidirectional (horizontal delivery) or by inability to modulate the intensity of the beam. Heavy compensators are typically used for beam modulation, which are not as flexible in modifying the fluence of the beam, relative to intensity-modulated proton therapy.

A considerable degree of interest has been elicited by two distinct single-room proton therapy systems currently in the design phase. The first, the Monarch 250 is being developed by Still River Systems (Littleton, MA). The Monarch 250 single-room system consists of a double-gantry-mounted superconducting cyclotron capable of producing $250 \mathrm{MeV}$ protons. In its current configuration, it is a passive scattering system that uses aperture and range compensators. This system applies the same proven technology that is currently used in all large multiroom proton therapy facilities. In the future, however, the system is expected to allow for intensity-modulated proton therapy (IMPT) delivery using spot scanning. The Monarch 250 will be capable of 2D/3D IGRT using large amorphous orthogonal Silicon panels and autoregistration or in-room 3D cone beam CT. Highprecision patient positioning will be achieved using a robotic couch that has three translational and three rotational degrees of freedom.

The second single-room proton solution is the TomoTherapy proton therapy system (Compact Particle Acceleration Corp, Madison, WI), which represents a dramatic departure from all current systems, in terms of both proton generation and delivery. The TomoTherapy proton therapy system is based on the concept of distal edge tracking (DET) or distal gradient tracking (DGT), using rotational delivery to deliver intensity-modulated proton therapy. To accelerate protons to a maximal energy of
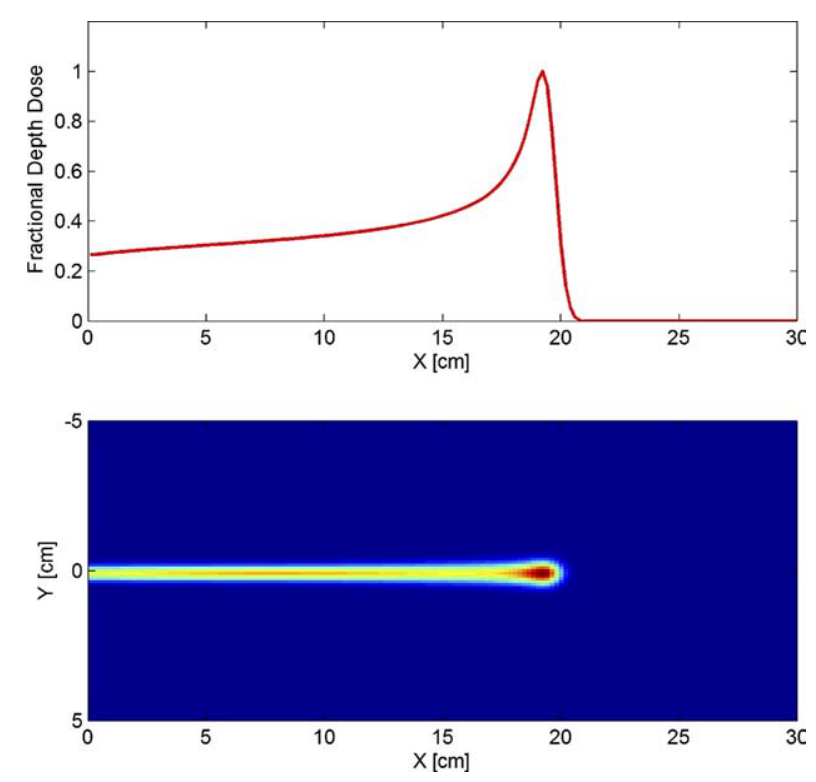

FIG. 8. Fractional depth dose in water of a $170 \mathrm{MeV}$ proton beam having a full-width half-maximum of $8 \mathrm{~mm}$. The associated proton pencil beam is shown below the fractional depth-dose curve.

$200 \mathrm{MeV}$, a dielectric wall linear accelerator will be used. Using a linear accelerator has the advantage that energy, intensity, and spot width are variable pulse to pulse. The system is projected to have nanosecond pulse lengths and a $50-\mathrm{Hz}$ pulse repetition rate. The TomoTherapy proton therapy system allows for rotational delivery using DET or DGT and fixed field delivery using spot scanning. The system will impart a lower neutron dose to patients, because neutrons are not produced in the aperture and range compensators; however neutrons will still be produced in the patient. Pretreatment image guidance will be accomplished using a conventional $\mathrm{kVCT}$ scanner mounted to the back of the unit.

Heavy ions, such as carbon, neon, nitrogen, argon, and silicon are also being investigated. These have the advantage of protons with a rapid fall-off (Bragg peak) but also possess a significantly higher RBE, similar to that of fast neutrons. There are three units worldwide (HIMAC and HARIMAC in Japan and GSI in Germany), and these centers are primarily carbon ion facilities. In the United States, efficacy using heavy ions is currently being evaluated, and there are as yet no centers.

Charged particle therapy has been investigated in a variety of disease sites. With prices exceeding $\$ 100$ million per unit, the cost-benefit ratio remains to be accurately described; efficacy data are still maturing. Diseases for which benefits have been seen with charged particles include uveal melanomas, ${ }^{51}$ optic pathway gliomas, ${ }^{52}$ skull-based tumors, ${ }^{53}$ pituitary adenomas, ${ }^{54}$ acoustic neuromas, ${ }^{55}$ nasopharynx and paranasal sinuses, ${ }^{56,57}$ spinal cord tumors, ${ }^{58,59}$ prostate cancer, ${ }^{60,61}$ lung cancer, ${ }^{62-65}$ gastrointestinal malignancies, ${ }^{66-68}$ and pediatric cancers. ${ }^{69-71}$ 


\section{CONCLUSIONS}

We have described the evolution of radiation techniques in the management of CNS malignancies. As software and hardware has improved, higher precision has been realized in targeting, as well as more conformal radiation. This has allowed higher doses of radiation to be delivered safely. Interest continues in particle therapy, because this may allow for a higher biological dose to the tumor with lower radiation exposure. Furthermore, as imaging technology for tumor delineation synchronously improves with radiation delivery technology, improvements in tumor control and continued reduction in toxicities should be expected.

\section{REFERENCES}

1. Daniel TM. Wilhelm Conrad Röntgen and the advent of thoracic radiology. Int J Tuberc Lung Dis 2006;10:1212-1214.

2. Perez CA, Halperin EC, Brady LW, Schmidt-Ullrich RK, editors. Principles and practice of radiation oncology. 4th ed. Philadelphia: Lippincott Williams \& Wilkins, 2004.

3. Bernier J, Hall EJ, Giaccia A. Radiation oncology: a century of achievements. Nat Rev Cancer 2004;4:737-747.

4. Emami B, Lyman J, Brown A, et al. Tolerance of normal tissue to therapeutic irradiation. Int J Radiat Oncol Biol Phys 1991;21:109122.

5. Mohan R, Wu Q, Manning M, Schmidt-Ullrich R. Radiobiological considerations in the design of fractionation strategies for intensity-modulated radiation therapy of head and neck cancers. Int J Radiat Oncol Biol Phys 2000;46:619-630.

6. Hall EJ. Intensity-modulated radiation therapy, protons, and the risk of second cancers. Int J Radiat Oncol Biol Phys 2006;65:1-7.

7. Huang E, Teh BS, Strother DR, et al. Intensity-modulated radiation therapy for pediatric medulloblastoma: early report on the reduction of ototoxicity. Int J Radiat Oncol Biol Phys 2002;52:599-605.

8. Gutiérrez AN, Westerly DC, Tomé WA, et al. Whole brain radiotherapy with hippocampal avoidance and simultaneously integrated brain metastases boost: a planning study. Int J Radiat Oncol Biol Phys 2007;69:589-597.

9. Roman DD, Sperduto PW. Neuropsychological effects of cranial radiation: current knowledge and future directions. Int J Radiat Oncol Biol Phys 1995;31:983-998.

10. Mizumatsu S, Monje ML, Morhardt DR, Rola R, Palmer TD, Fike JR. Extreme sensitivity of adult neurogenesis to low doses of X-irradiation. Cancer Res 2003;63:4021-4027.

11. Leksell L. The stereotaxic method and radiosurgery of the brain. Acta Chir Scand 1951;102:316-319.

12. Leksell L. Trigeminal neuralgia. Some neurophysiologic aspects and a new method of therapy [In Swedish]. Lakartidningen 1971; 68:5145-5148.

13. Stieber VW, Bourland JD, Tomé WA, Mehta MP. Gentlemen (and ladies), choose your weapons: gamma knife vs. linear accelerator radiosurgery. Technol Cancer Res Treat 2003;2:79-86.

14. Mehta M, Noyes W, Craig B, et al. A cost-effectiveness and cost-utility analysis of radiosurgery vs. resection for single-brain metastases. Int J Radiat Oncol Biol Phys 1997;39:445-454.

15. Larson DA, Bova F, Eisert D, et al.; Task Force on Stereotactic Radiosurgery, American Society for Therapeutic Radiology and Oncology. Current radiosurgery practice: results of an ASTRO survey. Int J Radiat Oncol Biol Phys 1994;28:523-526.

16. Stafford SL, Pollock BE, Foote RL, et al. Meningioma radiosurgery: tumor control, outcomes, and complications among 190 consecutive patients. Neurosurgery 2001;49:1029-1037; discussion 1037-1038.

17. Kondziolka D, Niranjan A, Lunsford LD, Flickinger JC. Stereotactic radiosurgery for meningiomas. Neurosurg Clin N Am 1999; $10: 317-325$.
18. Lee JY, Niranjan A, McInerney J, Kondziolka D, Flickinger JC, Lunsford LD. Stereotactic radiosurgery providing long-term tumor control of cavernous sinus meningiomas. J Neurosurg 2002;97:65-72.

19. Pollock BE, Stafford SL, Utter A, Giannini C, Schreiner SA. Stereotactic radiosurgery provides equivalent tumor control to Simpson grade 1 resection for patients with small- to medium-size meningiomas. Int J Radiat Oncol Biol Phys 2003;55:1000-1005.

20. Kreil W, Luggin J, Fuchs I, Weigl V, Eustacchio S, Papaefthymiou G. Long term experience of gamma knife radiosurgery for benign skull base meningiomas. J Neurol Neurosurg Psychiatry 2005;76: 1425-1430.

21. Zachenhofer I, Wolfsberger S, Aichholzer M, et al. Gamma-knife radiosurgery for cranial base meningiomas: experience of tumor control, clinical course, and morbidity in a follow-up of more than 8 years. Neurosurgery 2006;58:28-36; discussion 28-36.

22. Rogers L, Mehta M. Role of radiation therapy in treating intracranial meningiomas. Neurosurg Focus 2007;23(4):E4.

23. Flickinger JC, Kondziolka D, Niranjan A, Maitz A, Voynov G, Lunsford LD. Acoustic neuroma radiosurgery with marginal tumor doses of 12 to 13 Gy. Int J Radiat Oncol Biol Phys 2004;60:225230.

24. Pollock BE, Lunsford LD, Kondziolka D, et al. Outcome analysis of acoustic neuroma management: a comparison of microsurgery and stereotactic radiosurgery. Neurosurgery $1995 ; 36: 215-224$; discussion 224-229.

25. Régis J. New developments in the management of vestibular schwannomas in the modern era of radiosurgery [In French]. Neurochirurgie 2004;50:156-158.

26. Williams JA. Fractionated stereotactic radiotherapy for acoustic neuromas: preservation of function versus size. J Clin Neurosci 2003; $10: 48-52$.

27. Andrews DW, Suarez O, Goldman HW, et al. Stereotactic radiosurgery and fractionated stereotactic radiotherapy for the treatment of acoustic schwannomas: comparative observations of 125 patients treated at one institution. Int J Radiat Oncol Biol Phys 2001;50:1265-1278.

28. Fuss M, Debus J, Lohr F, et al. Conventionally fractionated stereotactic radiotherapy (FSRT) for acoustic neuromas. Int J Radiat Oncol Biol Phys 2000;48:1381-1387.

29. Meijer OW, Vandertop WP, Baayen JC, Slotman BJ. Single-fraction vs. fractionated linac-based stereotactic radiosurgery for vestibular schwannoma: a single-institution study. Int J Radiat Oncol Biol Phys 2003;56:1390-1396.

30. Sheehan JP, Kondziolka D, Flickinger J, Lunsford LD. Radiosurgery for residual or recurrent nonfunctioning pituitary adenoma. J Neurosurg 2002;97:408-414.

31. Landolt AM, Lomax N. Gamma knife radiosurgery for prolactinomas. J Neurosurg 2000;93 Suppl 3:14-18.

32. Pollock BE, Nippoldt TB, Stafford SL, Foote RL, Abboud CF. Results of stereotactic radiosurgery in patients with hormone-producing pituitary adenomas: factors associated with endocrine normalization. J Neurosurg 2002;97:525-530.

33. Friedman WA. Radiosurgery versus surgery for arteriovenous malformations: the case for radiosurgery. Clin Neurosurg 1999; $45: 18-20$.

34. Shaw E, Scott C, Souhami L, et al. Single dose radiosurgical treatment of recurrent previously irradiated primary brain tumors and brain metastases: final report of RTOG protocol 90-05. Int J Radiat Oncol Biol Phys 2000;47:291-298.

35. Andrews DW, Scott CB, Sperduto PW, et al. Whole brain radiation therapy with or without stereotactic radiosurgery boost for patients with one to three brain metastases: phase III results of the RTOG 9508 randomised trial. Lancet 2004;363:1665-1672.

36. Sanghavi SN, Miranpuri SS, Chappell R, et al. Radiosurgery for patients with brain metastases: a multi-institutional analysis, stratified by the RTOG recursive partitioning analysis method. Int J Radiat Oncol Biol Phys 2001;51:426-434.

37. Souhami L, Seiferheld W, Brachman D, et al. Randomized comparison of stereotactic radiosurgery followed by conventional radiotherapy with carmustine to conventional radiotherapy with carmustine for patients with glioblastoma multiforme: report of 
Radiation Therapy Oncology Group 93-05 protocol. Int J Radiat Oncol Biol Phys 2004;60:853-860.

38. Mahajan A, McCutcheon IE, Suki D, et al. Case-control study of stereotactic radiosurgery for recurrent glioblastoma multiforme. J Neurosurg 2005;103:210-217.

39. Maesawa S, Salame C, Flickinger JC, Pirris S, Kondziolka D, Lunsford LD. Clinical outcomes after stereotactic radiosurgery for idiopathic trigeminal neuralgia. J Neurosurg 2001;94:14-20.

40. Stone RS. Neutron therapy and specific ionization. Am J Roentgenol Radium Ther 1948;59:771-785.

41. Douglas JG, Lee S, Laramore GE, Austin-Seymour M, Koh W, Griffin TW. Neutron radiotherapy for the treatment of locally advanced major salivary gland tumors. Head Neck 1999;21:255263.

42. Douglas JG, Laramore GE, Austin-Seymour M, Koh W, Stelzer K, Griffin TW. Treatment of locally advanced adenoid cystic carcinoma of the head and neck with neutron radiotherapy. Int J Radiat Oncol Biol Phys 2000;46:551-557.

43. Laramore GE, Krall JM, Griffin TW, et al.; Radiation Therapy Oncology Group; Medical Research Council. Neutron versus photon irradiation for unresectable salivary gland tumors: final report of an RTOG-MRC randomized clinical trial. Int J Radiat Oncol Biol Phys 1993;27:235-240.

44. Griffin TW, Davis R, Laramore GE, Hussey DH, Hendrickson FR, Rodriguez-Antunez A. Fast neutron irradiation of metastatic cervical adenopathy: the results of a randomized RTOG study. Int J Radiat Oncol Biol Phys 1983;9:1267-1270.

45. Griffin TW, Pajak TF, Maor MH, et al. Mixed neutron/photon irradiation of unresectable squamous cell carcinomas of the head and neck: the final report of a randomized cooperative trial. Int J Radiat Oncol Biol Phys 1989;17:959-965.

46. Koh WJ, Krall JM, Peters LJ, et al. Neutron vs. photon radiation therapy for inoperable regional non-small cell lung cancer: results of a multicenter randomized trial. Int J Radiat Oncol Biol Phys 1993;27:499-505.

47. Laramore GE, Krall JM, Thomas FJ, et al. Fast neutron radiotherapy for locally advanced prostate cancer: final report of Radiation Therapy Oncology Group randomized clinical trial. Am J Clin Oncol 1993;16:164-167.

48. Fleurette F, Charvet-Protat S. [Proton and neutron radiation in cancer treatment: clinical and economic outcomes [In French]. Bull Cancer Radiother 1996;83 Suppl:223s-227s.

49. Forman JD, Shamsa F, Maughan RL, Duclos M, Orton C. Comparison of hyperfractionated conformal photon with conformal mixed neutron/photon irradiation in locally advanced prostate cancer. Bull Cancer Radiother 1996;83 Suppl:101s-105s.

50. Laramore GE, Griffith JT, Boespflug M, et al. Fast neutron radiotherapy for sarcomas of soft tissue, bone, and cartilage. Am J Clin Oncol 1989;12:320-326.

51. Gragoudas E, Li W, Goitein M, Lane AM, Munzenrider JE, Egan KM. Evidence-based estimates of outcome in patients irradiated for intraocular melanoma. Arch Ophthalmol 2002;120:1665-1671.

52. Fuss M, Hug EB, Schaefer RA, et al. Proton radiation therapy (PRT) for pediatric optic pathway gliomas: comparison with 3D planned conventional photons and a standard photon technique. Int J Radiat Oncol Biol Phys 1999;45:1117-1126.

53. Munzenrider JE, Liebsch NJ. Proton therapy for tumors of the skull base. Strahlenther Onkol 1999;175 Suppl 2:57-63.

54. Ronson BB, Schulte RW, Han KP, Loredo LN, Slater JM, Slater
JD. Fractionated proton beam irradiation of pituitary adenomas. Int J Radiat Oncol Biol Phys 2006;64:425-434.

55. Harsh GR, Thornton AF, Chapman PH, Bussiere MR, Rabinov JD, Loeffler JS. Proton beam stereotactic radiosurgery of vestibular schwannomas. Int J Radiat Oncol Biol Phys 2002;54:35-44.

56. Fitzek MM, Thornton AF, Varvares M, et al. Neuroendocrine tumors of the sinonasal tract. Results of a prospective study incorporating chemotherapy, surgery, and combined proton-photon radiotherapy. Cancer 2002;94:2623-2634.

57. Lin R, Slater JD, Yonemoto LT, et al. Nasopharyngeal carcinoma: repeat treatment with conformal proton therapy-dose-volume histogram analysis. Radiology 1999;213:489-494.

58. Nowakowski VA, Castro JR, Petti PL, et al. Charged particle radiotherapy of paraspinal tumors. Int J Radiat Oncol Biol Phys 1992;22:295-303.

59. Hug EB, Fitzek MM, Liebsch NJ, Munzenrider JE. Locally challenging osteo- and chondrogenic tumors of the axial skeleton: results of combined proton and photon radiation therapy using three-dimensional treatment planning. Int J Radiat Oncol Biol Phys 1995;31:467-476.

60. Shipley WU, Verhey LJ, Munzenrider JE, et al. Advanced prostate cancer: the results of a randomized comparative trial of high dose irradiation boosting with conformal protons compared with conventional dose irradiation using photons alone. Int J Radiat Oncol Biol Phys 1995;32:3-12.

61. Benk VA, Adams JA, Shipley WU, et al. Late rectal bleeding following combined X-ray and proton high dose irradiation for patients with stages T3-T4 prostate carcinoma. Int J Radiat Oncol Biol Phys 1993;26:551-557.

62. Bush DA, Slater JD, Shin BB, Cheek G, Miller DW, Slater JM. Hypofractionated proton beam radiotherapy for stage I lung cancer. Chest 2004;126:1198-1203.

63. Bonnet RB, Bush D, Cheek GA, et al. Effects of proton and combined proton/photon beam radiation on pulmonary function in patients with resectable but medically inoperable non-small cell lung cancer. Chest 2001;120:1803-1810.

64. Moyers MF, Miller DW, Bush DA, Slater JD. Methodologies and tools for proton beam design for lung tumors. Int J Radiat Oncol Biol Phys 2001;49:1429-1438.

65. Bush DA, Slater JD, Bonnet R, et al. Proton-beam radiotherapy for early-stage lung cancer. Chest 1999;116:1313-1319.

66. Chiba T, Tokuuye K, Matsuzaki Y, et al. Proton beam therapy for hepatocellular carcinoma: a retrospective review of 162 patients. Clin Cancer Res 2005;11:3799-3805

67. Matsuzaki Y, Osuga T, Chiba T, et al. New, effective treatment using proton irradiation for unresectable hepatocellular carcinoma. Intern Med 1995;34:302-304.

68. Bush DA, Hillebrand DJ, Slater JM, Slater JD. High-dose proton beam radiotherapy of hepatocellular carcinoma: preliminary results of a phase II trial. Gastroenterology 2004;127:S189S193.

69. Levin WP, Kooy H, Loeffler JS, DeLaney TF. Proton beam therapy. Br J Cancer 2005;93:849-854.

70. Hug EB, Sweeney RA, Nurre PM, Holloway KC, Slater JD, Munzenrider JE. Proton radiotherapy in management of pediatric base of skull tumors. Int J Radiat Oncol Biol Phys 2002;52:1017-1024.

71. Hug EB, Slater JD. Proton radiation therapy for pediatric malignancies: status report. Strahlenther Onkol 1999;175 Suppl 2:89-91. 